\section{Cómo manejar el cese de fumar}

La mayor parte de los fumadores en países como los Estados Unidos y el Reino Unido (RU) saben que la dependencia de la nicotina pone su vida en riesgo y desean dejar de fumar. En el RU, $78 \%$ lo intentan anualmente. Muchos lo repiten varias veces al año, pero solo de $2 \%$ a $3 \%$ logran cesar permanentemente. La nicotina produce dependencia al actuar sobre el mesencéfalo, donde se genera el impulso de fumar frente a estímulos asociados con el hábito. Los consecuentes cambios químicos producidos en el cerebro provocan intenso deseo de fumar cuando la persona se abstiene. Otro mecanismo de la dependencia se expresa en el mal humor y síntomas físicos desagradables que provoca la abstinencia y que se alivian al fumar. Así, la mayor parte de los intentos a solas fallan.

Aunque a menudo parece inútil tratar de ayudar a un fumador empedernido a cesar, los datos muestran la influencia que pueden tener los médicos según lo que digan y hagan sobre el tabaquismo durante las consultas. La forma más sencilla de apoyar es empezar por preguntar sobre el hábito, aconsejar el cese, evaluar la motivación y necesidad de farmacoterapia, ayudar con la prescripción o la inscripción en un programa de apoyo conductual, y luego seguir el progreso. Muchos pacientes responden positivamente a la idea, aunque no estuvieran pensando en intentarlo. El secreto está en ofrecerles ayuda y no simplemente instruir, regañar o aconsejar. Es crítico abandonar el tabaquismo antes de los 40 años. Pasada esa edad, se pierden 3 meses de esperanza de vida por cada año adicional en que se fuma. Un poco más de la mitad de los fumadores dejan el tabaquismo antes de morir, pero en muchos casos lo hacen muy tarde. El apoyo conductual puede brindarse aun por conferencia telefónica. Seguidamente se ofrecen recomendaciones basadas en datos científicos (base de datos Cochrane) y nuevas opciones de tratamiento para que los profesionales de salud contribuyan a que sus pacientes cesen de fumar exitosamente.

Todos los métodos de terapia sustitutiva (TS) como parches, chicles y pastillas son similarmente eficaces a largo plazo, con la ayuda de un profesional. Los parches de 24 horas se comienzan en la noche del último cigarrillo, aplicándose cada vez en lugares distintos del cuerpo. Hay que observar la reacción de la piel. Por otro lado, la abstinencia inicial es deprimente y el uso de antidepresivos se ha venido estudiando intensamente. En el RU se autoríza el uso de bupropión, que muestra ser dos veces más eficaz que otros medicamentos. Se comienza a usar una semana antes de dejar de fumar en un régimen de 8 semanas. Otro antidepresivo que se empieza a tomar días antes de cesar el hábito es la nortriptilina, que ha tenido buenos resultados con un tratamiento de 8 a 12 semanas. En otros ensayos, la vareniclina ha resultado aun más eficaz que el bupropión y la TS. La dosis inicial aumenta gradualmente por una semana, se suspende en la segunda durante la cual se deja de fumar y luego continúa por 12 semanas más. El médico tiene que estar atento a los efectos secundarios, si bien leves, que pueden causar esos medicamentos.

Las recaídas son de esperar durante el tratamiento o después, por lo que suele ser necesario empezar varias veces. Lamentablemente, hasta la fecha no se conoce ninguna intervención psicológica efectiva para evitar las recidivas. Por otra parte, es importante tener en cuenta la identidad social del fumador y subrayar el logro que significa su éxito. Por ej., los programas para embarazadas reducen la incidencia del nacimiento prematuro y bajo peso al nacer, y un gran número de ellas tratan de abandonar el hábito para no poner en riesgo la salud del feto. La nicotina se metaboliza 30\% más rápidamente durante el embarazo y hay que sopesar las ventajas y peligros de los diversos métodos. La TS con chicle, inhalador o un parche usado solamente durante el día minimizan la exposición del feto o lactante a la nicotina. En cuanto al tratamiento de adolescentes, en el Reino Unido el único método autorizado es la TS que, según indican diversos estudios, no es muy efectivo pues no se permite que los alumnos usen remedios con nicotina en las aulas y la única opción es el parche oculto bajo la ropa.

Actualmente continúa la investigación de otros medicamentos que puedan ayudar a cesar de fumar y de formas más eficaces de usar los que ya se conocen. No obstante, hay lagunas que llenar sobre el tema; a saber, por qué no trata de abandonar el hábito un mayor número de personas, por qué no usan los métodos disponibles y cómo reducir el riesgo de recidiva después del tratamiento. También interesa saber cómo disminuir el peligro de la inhalación del humo de tabaco en los fumadores que nunca lleguen a vencer su dependencia de la nicotina.

En la dirección electrónica http://pcpoh. bham.ac.uk/primarycare/research/stopsmoking. htm hay consejos para los médicos y en www.treat tobacco.net, información científica con guías, diapo- 
Instantáneas

sitivas y resúmenes, en diferentes idiomas, sobre el cese de fumar. (Aveyard P. Managing smoking cessation (clinical review). Br Med J. 2007;335:37-41.) 